\title{
TRANSFORMANDO VIDAS: UM RELATO DE EXPERIÊNCIA DA CONSTRUÇÃO DE UM GRUPO DE PESSOAS TRANS
}

\author{
LUIS FELIPE HATJE ${ }^{1}$
}

\begin{abstract}
Resumo: O presente artigo constitui um recorte de uma pesquisa de mestrado, que analisa a constituição de sujeitos transgêneros, que pretende, neste momento, apresentar o movimento de criação do grupo Transformando Vidas, localizado no município de Rio Grande/RS, e, em um segundo momento, pretende-se apontar os desdobramentos possibilitados a partir da criação do grupo. O grupo formado entre alunos/as universitários/as, do ensino básico e de professores/as da Universidade Federal do Rio Grande (FURG), pretende tecer uma rede de apoio a pessoas trans. Até esse momento, o grupo tem possibilitado uma maior visibilidade para os sujeitos que, até então, estavam à margem da sociedade. Nesse sentido, muitos espaços ainda precisam ser ocupados, mas unindo esforços, como o que está sendo construído com o grupo Transformando Vidas, é possível ir superando alguns obstáculos.

Palavras-chave: Experiência. Grupos Transgênero. Transexualidade.
\end{abstract}

Abstract: This article is a cross - section of a master 's research that analyzes the constitution of transgender subjects, which intends at this moment to present the creation movement of the group Transformando Vidas, located in the city of Rio Grande / RS. The group formed among university students, elementary school and teachers of the Universidade Federal do Rio Grande (FURG), intends to create a network of support for trans people. Until that moment, the group has made possible a greater visibility for the subjects who, until then, were at the margin of the society. In this sense, many spaces still need to be occupied, but joining efforts, such as what is being built with the Transformando Vidas group, it is possible to overcome some obstacles.

Keywords: Experience. Transgender Groups. Transsexuality.

Resumen: El presente artículo constituye un recorte de una investigación de maestría, que analiza la constitución de sujetos transgéneros, que pretende, en este momento, presentar el movimiento de creación del grupo Transformando Vidas, localizado en el municipio de Rio Grande/RS. El grupo formado entre alumnos/as universitarios/as, de la enseñanza básica y de profesores / as de la Universidade Federal do Rio Grande (FURG), pretende tejer una red de apoyo a personas trans. Hasta ese momento, el grupo ha posibilitado una mayor visibilidad para los sujetos que, hasta entonces, estaban al margen de la sociedad. En ese sentido, muchos espacios todavía necesitan ser ocupados, pero uniendo esfuerzos, como lo que está siendo construido con el grupo Transformando Vidas, es posible ir superando algunos obstáculos.Palabras clave: Experiencia. Grupos Transgénero. Transexualidad.

\footnotetext{
${ }^{1}$ Mestrando do Programa de Pós-graduação em Educação em Ciências Química da Vida e Saúde da Universidade Federal do Rio Grande (FURG). Bacharel em Direito pela Universidade Federal do Rio Grande (FURG). Participante do Grupo de Pesquisa Sexualidade e Escola - GESE.
}

Rev. Diversidade e Educação, v. 5, n. 1, p. 57-64, jan./jun. 2017. 


\section{Introdução}

Esse artigo constitui um recorte de uma pesquisa de mestrado, que analisa a constituição de sujeitos transgêneros. Nesse sentido, a experiência relatada é o resultado dos desdobramentos possibilitados a partir da construção do grupo Transformando Vidas. Diante da emergência da temática da transgeneridade, o Grupo de Pesquisa Sexualidade e Escola (GESE) - que durante quinze anos vem problematizando discussões acerca dos corpos, gêneros e sexualidades, no âmbito da Universidade Federal do Rio Grande (FURG) - percebendo as demandas de alunos/as transgêneros/as, inicialmente, no espaço universitário buscou uma proposta para contribuir com estes sujeitos de forma que pudessem compartilhar vivências entre si. Nesse sentido, o GESE articulou a criação de um grupo de apoio entre os/as alunos/as trans e que fosse interligado com diversos segmentos de profissionais para que pudessem atenuar as demandas dos sujeitos transgêneros dentro do espaço acadêmico e escolar.

\section{Os primeiros passos do Grupo Transformando Vidas}

Nesse sentido, o Grupo Transformando Vidas ${ }^{2}$, inicia no primeiro semestre do ano de 2016 com o objetivo de tecer uma rede de apoio a pessoas transgêneras, no sentido de estabelecer relações entre diferentes profissionais que poderiam contribuir com aspectos relacionados a saúde, educação, direitos, acesso a cidadania e a demais questões que permeiam a vida de sujeitos que possuem algumas demandas especificas em razão de sua identidade de gênero.

Para além disso, o grupo possibilita que pessoas transgêneras, na sua maioria estudantes da universidade de diferentes faixas etárias, cursos e em diferentes momentos acadêmicos, bem como estudantes do ensino básico, além de pessoas trans que estivessem fora dos bancos escolares, estejam interligados/as e possam compartilhar experiências e descobertas entre si, servindo um de apoio e suporte para o outro.

Dentre as atividades também realizamos discussões teóricas sobre identidade de gênero, transgeneridade, marcadores corporais, entre outras.

\footnotetext{
${ }^{2} \mathrm{O}$ nome do grupo foi escolhido após ampla discussão pelos/as seus/suas integrantes transgêneros. Em ato contínuo, criou-se um grupo no website Facebook e no aplicativo de celulares WhatsApp para que pudessem compartilhar informações e manterem contato entre si.
}

Rev. Diversidade e Educação, v. 5, n. 1, p. 57-64, jan./jun. 2017. 
Nesse momento, cabe explicar que identidade de gênero é algo discursivo, cultural e pode ultrapassar o dispositivo binário de gênero, considerando que se refere à forma pela qual o indivíduo se enxerga independente do sexo atribuído em seu nascimento. As transidentidades são uma das formas mais evidentes desta concepção de ultrapassar os limites binários impostos pela sociedade. Consoante Hovarth (2009), transgênero:

é um termo amplo que denota diversos fenômenos em que os indivíduos não se enquadram nas categorias de sexo/gênero que lhes são atribuídas ao nascer, desempenhando, em vez disso, papéis sociais que não são normalmente associados ao seu sexo natal, diferindo dessa forma da respectiva norma de gênero $(2009$, p. 383)

Assim, o conceito transegênero é um conceito bastante amplo que abarca uma população diversifica de sujeitos que não se identificam, em graus diferentes, com os papéis esperados do gênero que lhes foi determinado ao nascer. Nesse sentido, para Letícia Lanz (2015, p. 83)

O termo 'transgênero', surgiu assim, como um denominador comum dentro do pantanal terminológico das identidades gênero-divergentes, classificando todos os seus membros com base nos seus desvios relativamente ao comportamento socialmente esperado do gênero em que forma classificados ao nascer.

Dessa forma, o conceito pode ser aplicado aos indivíduos que, em tempo integral, parcial ou em momentos e/ou situações específicas da vida, apresentam algum grau de desconforto ou se comporte de maneira que esteja desconforme do binômio oficial de gênero. Porém, salienta que às inúmeras disputas entre as identidades gênero-divergentes, o termo não é consenso por todos/as como designação geral para todas as identidades (LANZ, 2015).

\section{Os encontros do grupo}

O grupo Transformando Vidas iniciou com uma reunião com a presença de três integrantes do GESE e cerca de quatro alunos/alunas trans da universidade e da escola. No primeiro encontro foram combinados, entre muitas coisas, como seriam os encontros e a sua regularidade. Deste modo, ficou estipulado que as reuniões ocorreriam na sala do GESE, no mínimo uma vez por mês, em um horário em que a maioria dos/das seus/suas integrantes pudesse participar, sendo que foi acordado que para o ingresso de novas

Rev. Diversidade e Educação, v. 5, n. 1, p. 57-64, jan./jun. 2017. 
pessoas no grupo o nome do/a interessado/a deveria ser aceito pelos membros, considerando que o grupo foi construído com o objetivo de ser um espaço onde todos/as os/as seus/suas integrantes estivessem tranquilos para conversar sobre aspectos pessoais e que muitas vezes envolveriam questões emocionais.

Depois da realização do primeiro encontro, o grupo passou a trazer enquanto pautas de suas reuniões as demandas que iam sendo levantadas pelos/as seus/suas integrantes, assim os assuntos que surgiam mobilizavam a todos e todas para problematizar as questões.

As reuniões do grupo são marcadas por uma rodada de apresentações quando há presença de um/a integrante novo/a ou de algum/a convidado/a e, posteriormente, todos/as possuem um espaço para falar como estão se sentindo, sobre a sua vida acadêmica ou profissional, questões familiares e, sobretudo, compartilharem suas vivências, o que permite que possam desenvolver um sentimento de pertencimento ao grupo.

Com relação as pautas do grupo, surge, logo de início, as preocupações atinentes a assistência à saúde, especialmente com relação ao corpo destes sujeitos. Neste momento, aparece o desejo, por parte de alguns/mas deles/as, de buscar tratamentos hormonais com o propósito de adequar seu corpo ao gênero do qual se identificam.

Consequentemente, o grupo sentiu a necessidade de expandir a sua rede de apoio com o objetivo de atender a demanda da saúde dos seus membros, dessa forma, o grupo passou a buscar parceiros/as junto ao Hospital Universitário da FURG. Diante disso, se entrou em contato com a ginecologista do hospital para estabelecer um suporte de saúde, a qual se mostra bastante receptiva a ideia e passa a realizar um movimento com diferentes especialidades e campos do saber médico.

Depois da realização desta articulação, a reunião seguinte do "Transformando Vidas" ocorreu nas dependências do Hospital Universitário da FURG, com a presença da ginecologista, que aproximou, também, do grupo um urologista, uma enfermeira e uma psicóloga, além dos demais membros do grupo que realizam o seu primeiro encontro fora da universidade.

$\mathrm{Na}$ reunião que ocorreu dentro do hospital, com a presença de diferentes profissionais da área da saúde dispostos a esclarecer muitas das angústias e dúvidas das pessoas trans do grupo, são dados encaminhamentos para que os/as integrantes do grupo

Rev. Diversidade e Educação, v. 5, n. 1, p. 57-64, jan./jun. 2017. 
possam marcar consultas com os médicos/as, enfermeira e psicóloga que passam então a compor um dos eixos de apoio e suporte do grupo.

Esse movimento realizado junto da equipe de saúde, dentro do Hospital Universitário, desencadeou na idealização da criação de um Ambulatório de Gênero que fosse direcionado a pessoas que não se enquadram dentro daquele gênero que socialmente se espera. A ideia foi criar um espaço onde estes sujeitos tivessem a sua disposição os principais procedimentos que precisassem, sobretudo com tratamento endocrinológico, ginecológico, proctológico e de Saúde Mental. E que se constituísse enquanto um espaço que voltasse o olhar para esses sujeitos com o respeito que se quer.

O Ambulatório de Saúde está se articulando e há uma mobilização por parte dos/as profissionais para a sua efetiva implementação. É importante mencionar que o atendimento médico e psicológico já está sendo realizado, e, neste sentido, basta que o sujeito transgênero realize um contato com um dos/as profissionais que articula a rede para que seja agendada a sua consulta, que acaba muitas vezes sendo priorizada pela equipe do hospital. Esse atendimento tem possibilitado que esses/as alunos/as tenham realizado consultas e exames, fato que muitos/as relatam ser extremamente importante, pois em outros momentos de suas vidas tinham sofrido muito preconceito de profissionais da área da saúde.

\section{A demanda judicial de retificação do nome e do gênero nos registros civis}

Para além dos temas que envolviam questões de saúde, um assunto que lhes toca muito é a questão da retificação do nome civil. Deste modo, por tratar-se de uma questão que interessou boa parte dos/as seus/suas integrantes, iniciamos uma discussão sobre os significados do nome e como isso vinha sendo produzido nos diversos espaços onde os sujeitos transitam.

O momento foi marcado pela troca de vivências, pelo compartilhamento de algumas conquistas nesta seara, como, por exemplo, a utilização do nome pelo qual eles/as desejavam ser chamados/as já em documentos oficiais dentro da universidade, no cartão do ônibus e até mesmo no cartão do Sistema Único de Saúde - SUS, mas, também, ouvimos relatos sobre os constrangimentos, "piadas" e discriminações durante suas vidas e que acabavam por afetar o seu convívio social. Diante disso, mobilizamos nossas ações para tentar achar algumas soluções rápidas para essa questão.

Rev. Diversidade e Educação, v. 5, n. 1, p. 57-64, jan./jun. 2017. 
Nesta primeira discussão sobre a alteração do nome não tínhamos muito conhecimento sobre os procedimentos necessários para dar prosseguimento a demanda dos membros do grupo, sobretudo quanto a retificação do registro civil e a alteração do gênero nos registros e documentos de identificação oficiais do Estado.

Procuramos recolher a maior quantidade de informações sobre o processo para solicitar a mudança do nome civil para discutirmos na próxima reunião. Deste modo, buscamos informações junto do ativista pelos Direitos Humanos, Toni Reis, que estabeleceu um contato com uma advogada do Ceará com experiência na temática e que nos encaminhou um roteiro dos procedimentos que deveriam ser adotados para dar início ao processo.

Ainda na busca de reunir informações e cientes de que precisaríamos de um/a advogado/a ou Defensor/a Público/a para ajuizar uma ação na justiça, procuramos articular uma forma que fosse mais conveniente para o grupo. Por isso entramos em contato com o advogado do Centro de Referências em Direitos Humanos - CRDH, da Universidade Federal do Rio Grande - FURG, que recebeu os/as integrantes do GESE para compor mais uma parceria do grupo de apoio.

Na reunião com o advogado do CRDH - FURG, soubemos que o centro já possuía um certo número de sujeitos que buscavam a retificação do nome civil. De posse de todas essas informações, agendamos uma reunião com os/as integrantes do grupo para contar as novidades e saber quem estava interessado/as em dar continuidade ao processo.

Assim, depois de reunidos todos documentos, agendamos uma data junto do advogado do CRDH-FURG, para ouvir os relatos, um a um dos/as interessados/as e contar um pouco da sua história para fundamentar o processo judicial para ingressar no judiciário.

Depois de realizadas as entrevistas realizadas com o advogado sobre o processo de retificação do nome com as pessoas trans que ingressaram no judiciário e reunidos todos os documentos necessários, os/as estudantes foram chamados para assinar as procurações para que o processo pudesse ser ajuizado.

Toda a discussão e a mobilização em busca da adequação dos documentos dos sujeitos aos fatos de suas vidas têm suscitado inúmeras reflexões acerca da importância do nome na vida das pessoas. Dentro disso, começa a surgir a questão do nome das pessoas trans que não são chamadas pelo nome que se reconhecem, mas pelo nome de

Rev. Diversidade e Educação, v. 5, n. 1, p. 57-64, jan./jun. 2017. 
registro e, disso, decorrem questões relacionadas à inserção social, família e no mercado de trabalho e, também que envolvam o preconceito.

\section{Conclusão}

Dito isso, acompanhando o andamento do grupo, percebeu-se que o grupo foi se constituindo a partir de uma rede de amigos/as, dentre sujeitos transgêneros/as e profissionais da área da educação, do direito e da saúde. Assim, sempre que alguém do grupo precisa de algo, eles/as podem contar com os/as parceiros/as da rede de apoio que são pessoas que estão imersas nas discussões do grupo e conhecem as principais demandas deste.

A partir da formação do grupo, bem como as discussões e vivências que o mestrado tem possibilitado e, mais especificamente, com os debates com e sobre sujeitos trans, forjamos uma nova rede de significados acerca dos gêneros e que tem permitido enxergar essas questões de outra forma.

Diante disso, a questão da transgeneridade passa a ser vista com outros óculos teóricos ${ }^{3}$ que permitem perceber toda uma trama discursiva em torno deste assunto. Assim, nestes últimos meses, de mestrado e de participação no grupo, passamos a prestar atenção em elementos sociais que antes passavam despercebidos e que neste processo começam a nos tocar.

Portanto, a formação do grupo vem possibilitando para os seus integrantes a construção de toda uma rede discursava em volta da transgeneridade. E, desse modo, percebemos que os corpos, a sexualidade e a vida dos sujeitos trans é discutida rotineiramente em diferentes espaços sociais o que tem garantido uma maior visibilidade para os sujeitos que até então estavam colocados à margem da sociedade. Nesse sentido, muitos espaços ainda precisam ser ocupados, mas unindo esforços, como o grupo Transformando Vidas, é possível ir superando alguns obstáculos.

\section{Referências:}

HORVATH, Aleksandra. Gender Transgression. In. O'BRIEN, Jodi (ed.). Encyclopedia of Gender and Society. Thousand Oaks-CA: Sage, 2009.

\footnotetext{
${ }^{3}$ A metáfora dos "óculos teórico", diz respeito ao olhar que o/a pesquisador/a, a partir de seu arcabouço teórico, volta para o seu objeto de pesquisa.
}

Rev. Diversidade e Educação, v. 5, n. 1, p. 57-64, jan./jun. 2017. 
LANZ, Letícia. O corpo da roupa: a pessoa transgênera entre a transgressão e a conformidade com as normas de gênero. Curitiba: Transgente, 2015.

Recebido em: 12/06/2017

Aceito em: 12/10/2017

Rev. Diversidade e Educação, v. 5, n. 1, p. 57-64, jan./jun. 2017. 